\title{
NOTAS DE JURISPRUDENCIA DEL TRIBUNAL EUROPEO DE DERECHOS HUMANOS
}

\author{
OMAR BOUAZZA ARIÑO \\ Universidad Complutense de Madrid ${ }^{1}$
}

Cómo citar/Citation

Bovazza Ariño, O. (2021).

Notas de jurisprudencia del Tribunal Europeo de Derechos Humanos.

Revista de Administración Pública, 216, 363-386.

doi: https://doi.org/10.18042/cepc/rap.216.13

\section{SUMARIO}

I. LAS MEDIDAS ADOPTADAS EN VIRTUD DEL ESTADO DE URGENCIA NO IMPLICAN UNA VIOLACIÓN DEL DERECHO A LA LIBERTAD. II. DERECHO A UN PROCESO EQUITATIVO (I): INJERENCIA DEL PODER EJECUTIVO Y DEL LEGISLATIVO EN EL NOMBRAMIENTO DE JUECES: 1. Injerencia en el Tribunal Supremo. 2. Injerencia en el Tribunal Constitucional. III. DERECHO A UN PROCESO EQUITATIVO (II): DERECHO A RECURRIR UNA DECISIÓN ADMINISTRATIVA ANTE UN TRIBUNAL. IV. DERECHO A UN PROCESO EQUITATIVO (III): ARBITRARIEDAD EN LA ADMISIÓN DEL RECURSO DE CASACIÓN. V. DERECHO AL RESPETO DE LA VIDA PRIVADA Y FAMILIAR: DIGNIDAD DEL CUERPO HUMANO TRAS LA MUERTE Y LIBERTAD DE INVESTIGACIÓN CIENTÍFICA. VI. LIBERTAD DE EXPRESIÓN: 1. Banderas reivindicativas. 2. Redes sociales y discurso xenófobo. El gestor de la cuenta es responsable de los comentarios de sus seguidores. 3. Sanciones disciplinarias. VII. PROHIBICIÓN DE DISCRIMINACIÓN EN EL OTORGAMIENTO DE AYUDAS FAMILIARES EN SITUACIONES ANÁLOGAS.

obouazza@der.ucm.es Este trabajo ha sido realizado en el seno del proyecto "La europeización de las sanciones administrativas: la incidencia del derecho europeo en el concepto de sanción, en sus garantías y en su función" (PID2020-115714GB-I00), financiado por la Agencia Estatal de Investigación. 


\section{LAS MEDIDAS ADOPTADAS EN VIRTUD DEL ESTADO DE URGENCIA NO IMPLICAN UNA VIOLACIÓN DEL DERECHO A LA LIBERTAD}

En la decisión de inadmisión recaída en el caso Cristian-Vasile TERHEŞ c. Rumanía, de 13 de abril de 2021, el demandante es un diputado del Parlamento europeo. Vive en la ciudad rumana de Zalău.

Como se sabe, la Organización Mundial de la Salud declaró, el pasado 11 de marzo de 2020, la pandemia mundial causada por el coronavirus SARS-COV-2, responsable de la enfermedad infecciosa respiratoria denominada COVID-19.

El presidente de Rumanía aprobó el Decreto no 195, de 16 de marzo de 2020, por el que se instituye el estado de urgencia para todo el territorio rumano, por una duración de treinta días ${ }^{2}$. Entró en vigor con carácter inmediato. El decreto restringía algunos derechos fundamentales, como la libertad de movimiento.

Hay que subrayar que la declaración, debido, precisamente, al impacto en los derechos humanos de los ciudadanos, no se adoptó teniendo en consideración únicamente el orden interno. En efecto, la representación permanente de Rumanía en el Consejo de Europa, el 17 de marzo de 2020 informó a la Secretaría General del Consejo de Europa la intención de Rumanía de aplicar el art. 15 $\mathrm{CEDH}$, esto es, la derogación de las obligaciones emanadas del convenio en caso de estado de excepción "en la estricta medida en que lo exija la situación" (art. 15.1 CEDH). Las autoridades rumanas, además, comunicaron periódicamente las medidas adoptadas hasta la finalización del estado de urgencia en la fecha indicada.

El Ministro del Interior dictó una ordenanza el 21 de marzo de 2020 por la que se recomendaba a los ciudadanos no salir de casa entre las 6:00 y las 22:00, prohibiéndolo de dicha hora a las 6:00. Debido al empeoramiento de la situación sanitaria, el 24 de marzo de 2020 se dictó una nueva ordenanza por la que se prohibía cualquier movimiento fuera del hogar con efecto inmediato, excepto en una serie de casos contemplados específicamente. Cualquier persona que abandonara su domicilio debía portar un documento que acreditara las razones justificativas para ello. La infracción de la norma se sancionaba con una multa.

El 14 de abril de 2020, tras evaluar la situación de salud pública del país, el presidente de Rumanía aprobó el Decreto 240/2020, por el que se extendió el estado de urgencia treinta días más, hasta el 14 de mayo de 2020, por lo que se mantenían las medidas adoptadas hasta la fecha. El estado de urgencia concluyó el 14 de mayo de 2020 a medianoche.

El demandante dice que el confinamiento adoptado del 24 de marzo de 2020 a 14 de mayo de 2020 le afectó personalmente. El 7 de mayo de 2020

2 Puede consultarse en el siguiente enlace: DECRET 195 16/03/2020 - Portal Legislativ (just.ro) (última consulta, 1 de agosto de 2021). 
interpuso un recurso ante el Tribunal de Bucarest en base al art. 5.4 del Convenio según el cual:

Toda persona privada de su libertad mediante arresto o detención tendrá derecho a presentar un recurso ante un órgano judicial, a fin de que se pronuncie en breve plazo sobre la legalidad de su detención y ordene su puesta en libertad si dicha detención fuera ilegal.

El señor Terheş argumentó que, a su modo de ver, fue víctima de una detención administrativa. Pidió al Tribunal que examinara su caso urgentemente y dictara una sentencia. El 8 y el 25 de mayo de 2020 presentaría nuevas solicitudes de reconsideración de la normativa aprobada en virtud del estado de urgencia. Sus solicitudes fueron rechazadas al considerarse que la normativa en cuestión no era susceptible de revisión administrativa.

Agotada la vía interna, el demandante acude ante el TEDH alegando una violación del art. 5.1 (derecho a la libertad y a la seguridad). Considera que el confinamiento impuesto en Rumanía del 24 de marzo al 14 de mayo de 2020 ha supuesto una privación de su derecho a la libertad.

El TEDH, en primer lugar, señala que el demandante no ha invocado el art. 2 del Protocolo $n^{\circ}$ 4, que reconoce el derecho a la libertad de movimiento. El demandante, por ello, deberá demostrar que el confinamiento general impuesto ha constituido una privación de la libertad y no una simple restricción de su libertad de movimiento.

Con la finalidad de determinar si la medida adoptada ha implicado una privación de libertad, el TEDH examinará la situación individual del demandante a la luz de los criterios establecidos por su jurisprudencia.

El TEDH observa que la medida de la que se queja el demandante hay que tenerla en consideración en un contexto concreto y específico. El TEDH observa que el confinamiento ha sido impuesto en el marco del estado de urgencia, instaurado en Rumanía desde el 16 de marzo de 2020, por razones sanitarias. El estado de urgencia, según la ley rumana, es un régimen jurídico especial que permite adoptar un conjunto de medidas excepcionales que derogan el orden constitucional establecido. Por lo tanto, procede en caso de peligro inminente o en curso, de duración determinada en el tiempo y permite al Estado adoptar medidas que impliquen la restricción del ejercicio de determinadas libertades fundamentales. A modo de ver del TEDH, no hay duda de que la pandemia de la COVID-19 puede tener efectos muy graves no solo en la salud, sino también en la sociedad, en la economía y en el funcionamiento del Estado y en la vida en general y que la situación debe calificarse de contexto excepcional imprevisible, como lo expresa el Decreto 195/2020 en su preámbulo.

El TEDH observa que la medida de la que se queja el demandante tenía la finalidad de aislar y confinar al conjunto de la población por razones sanitarias que las autoridades han valorado como graves y urgentes. Como subraya el preámbulo del Decreto 195/2020, el presidente rumano decidió instaurar el 
estado de urgencia después de consultar a los órganos competentes, en un contexto excepcional imprevisible debido a la situación epidémica internacional en la que el coronavirus SARS-CoV-2 se ha propagado por todo el mundo por lo que, como se sabe, la OMS ha declarado que se trata de una pandemia. El decreto establece asimismo que si las autoridades internas no adoptaban medidas de carácter excepcional urgentemente, su inactividad habría tenido un impacto muy grave, principalmente en el derecho a la vida y, subsidiariamente, en el derecho a la salud. Así, con la finalidad de atenuar el impacto económico y social de la epidemia y de proteger el derecho a la vida, el Estado ha adoptado progresivamente medidas como el confinamiento de la población.

A continuación, el TEDH analiza si el confinamiento decretado ha sido una privación de libertad en base a los criterios elaborados por su jurisprudencia.

El TEDH constata que el confinamiento ha durado 52 días. En concreto, del 24 de marzo de 2020 al 14 de mayo de 2020. El TEDH tendrá en cuenta la modalidad de confinamiento, sus efectos y las medidas adoptadas para su ejecución, a la luz del contexto en el que se aprobó.

En cuanto al confinamiento y las modalidades de ejecución, el TEDH observa que no se trató de una medida preventiva individual. Se trató de una medida de aplicabilidad general a toda la población adoptada por textos normativos aprobados por diferentes autoridades rumanas. Como consecuencia de la aplicación de la medida, toda la población, incluido el demandante, debía permanecer en sus hogares. Solo se permitiría la salida en los casos previstos en la norma, debidamente justificados, como antes se ha indicado.

Por tanto, el TEDH observa que el demandante podía salir de su casa en base a razones justificadas contempladas por la norma y que la Administración pública no le sometió a una vigilancia individual. El demandante no ha alegado que haya sido obligado a vivir en un lugar exiguo ni que se le haya impedido mantener contactos sociales.

El TEDH también considera relevante que el demandante no ha expuesto los efectos que la medida le ha ocasionado. El demandante no ha alegado que haya tenido que estar totalmente encerrado todo el tiempo que ha durado el confinamiento severo ni ha explicado cómo lo ha vivido efectivamente.

A la vista de los elementos expuestos, el TEDH considera que la gravedad de las restricciones en la libertad de movimiento alegadas por el demandante no han tenido una intensidad suficiente. No se puede concluir que el confinamiento decretado en Rumanía ha supuesto una privación de libertad. El TEDH subraya, por ello, que el demandante no ha sido privado de su libertad en el sentido del art. 5.1 CEDH. En consecuencia, no analizará si la medida estaba justificada en base al art. 5.1.e). Por todo ello, el TEDH inadmite la demanda ${ }^{3}$.

3 La pandemia ocasionada por la COVID-19 ha implicado la aplicación de toda una serie de medidas preventivas y precautorias debido a una amenaza transfronteriza. Ha puesto de manifiesto la necesidad de dar una respuesta jurídica adecuada y efectiva ante los riesgos 


\section{DERECHO A UN PROCESO EQUITATIVO (I): INJERENCIA DEL PODER EJECUTIVO Y DEL LEGISLATIVO EN EL NOMBRAMIENTO DE JUECES}

\section{INJERENCIA EN EL TRIBUNAL SUPREMO}

En la sentencia recaída en el caso Reczkowicz c. Polonia, de 22 de julio de 2021, la demandante es abogada. Fue suspendida de ejercicio durante tres ańos debido a varios incidentes acontecidos en la representación de un cliente. Recurrió la decisión ante los tribunales. Su recurso finalmente fue desestimado en 2019 por la cámara disciplinaria del Tribunal Supremo, una de las nuevas cámaras creadas a raíz de las reformas del sistema judicial.

En base al art. $6 \mathrm{CEDH}$ (derecho a un proceso equitativo), la demandante alega que su caso no ha sido decidido por un tribunal independiente e imparcial establecido por la ley. En concreto, alega que los jueces de la cámara disciplinaria que han examinado su caso han sido nombrados por el presidente de Polonia por recomendación del Consejo Nacional de la Magistratura (CNM) en violación del derecho interno y de los principios de la preeminencia del derecho, de la separación de poderes y de la independencia del poder judicial. Afirma que la nueva cámara disciplinaria es política y que su verdadero objeto es la supresión de toda oposición judicial a los cambios aportados al sistema jurídico polaco por el gobierno actual.

El TEDH analizará el caso a la luz de los criterios establecidos por la Gran Sala en el asunto Gudmundur Andri Ástrádsson c. Islandia, de 1 de diciembre de 2020.

El TEDH constata que ha habido una violación manifiesta del derecho interno que ha dado lugar a una infracción de las normas procesales básicas para el nombramiento de los jueces en la cámara disciplinaria del TS. En efecto, el CNM, surgido de la ley de reforma de este órgano, de 8 de diciembre de 2017, no presenta garantías suficientes de independencia de los poderes legislativo y ejecutivo. El TEDH estima que un procedimiento de nombramiento de los jueces indebidamente influido por los poderes legislativo y ejecutivo es incompatible con el art. 6.1 del convenio. En concreto, la ley de reforma de 2017 ha privado al poder judicial del derecho a elegir a los miembros judiciales del CNM, derecho que disponía en virtud de la legislación anterior, lo que significa que los poderes legislativo y ejecutivo pueden interferir directa o indirectamente en el nombramiento de los jueces.

Las irregularidades en el procedimiento de nombramiento han afectado a la legitimidad de la cámara disciplinaria del TS en la medida en que se trata de un

que trascienden el plano nacional, tema sobre el que han estudiado recientemente Fernando González Botija (dir.), Pedro Díaz Peralta y Antonio Juberías Sánchez (coords.) (2021), Riesgos emergentes. Tutela jurídica efectiva y desafíos regulatorios, Barcelona: Atelier. 
procedimiento intrinsecamente defectuoso, por lo que no posee los atributos de un "tribunal legal" en el sentido del convenio.

Para llegar a esta conclusión el TEDH se ha referido a los asuntos del TS polaco de diciembre de 2019 y enero de 2020 que constatan que el proceso de nombramiento de los jueces de la cámara disciplinaria violaban el derecho interno. El TEDH estima que esos asuntos se fundamentan en razones convincentes en base a una evaluación en profundidad y detallada del derecho polaco relevante a la luz de las normas fundamentales del convenio y del derecho de la Unión Europea. Tiene igualmente en cuenta las resoluciones del Tribunal de Justicia de la Unión Europea sobre este tema, así como múltiples informes y evaluaciones de instituciones europeas e internacionales.

El TEDH concluye que la cámara disciplinaria del Tribunal Supremo, que ha examinado el caso de la demandante, no era un tribunal establecido por la ley. Las irregularidades en el procedimiento de nombramiento comprometen su independencia e imparcialidad. Ha habido, por tanto, una violación del art. 6.1 del convenio.

\section{INJERENCIA EN EL TRIBUNAL CONSTITUCIONAL}

En la sentencia recaída en el caso Xero Flor W Polsce sp. z o.o c. Polonia, de 7 de mayo de 2021, la empresa demandante es una productora de césped. Plantea una reclamación de indemnización por los daños ocasionados por la caza del ciervo y el jabalí en sus tierras. El asunto culmina la vía ordinaria e impugna ante el TC. El TC inadmitió en julio de 2017.

La demandante considera que la sentencia del TC está viciada, pues el Alto Tribunal no estaba constituido de conformidad con la ley. En concreto, la demandante cuestionaba la legalidad del nombramiento de uno de los jueces.

Durante la última sesión de la cámara baja del Parlamento (en adelante, me referiré a su denominación en polaco, Sejm) de su séptima legislatura, en octubre de 2015, había aprobado resoluciones por las que se elegía a cinco magistrados para sustituir a aquellos cuyo mandato estaba llegando a su fin. Tres de los magistrados del TC habrían terminado su mandato durante esa legislatura del Sejm. Los magistrados no prestarían juramento ante el presidente de la República.

En noviembre de 2015 el nuevo Sejm de la octava legislatura adoptó resoluciones sobre la falta de efecto legal de la elección de esos cinco jueces por parte del anterior Sejm y en diciembre eligió a cinco nuevos jueces para el TC, incluido M.M. Los jueces en este caso sí prestarían juramento ante el presidente de la República.

El TC, en una sentencia de 3 de diciembre de 2015, confirmada en varias sentencias posteriores, encontró varias incompatibilidades con la Constitución en la elección de los jueces. En concreto, dijo que la elección por el Sejm en la octava legislatura de tres de los jueces, de entre ellos, M.M., fue inválida, al haberse realizado de conformidad con una norma que había sido declarada 
inconstitucional. Por ello, la empresa demandante acude ante el TEDH alegando que la elección de M.M., que participó en la decisión de inadmisión que le afectó, de julio de 2017, no fue válida. La decisión de inadmisión estaría viciada, como he apuntado antes.

El TEDH no encuentra razones para separarse del criterio del TC según el cual hubo irregularidades en el nombramiento de magistrados. El TEDH dice que las acciones del poder legislativo y ejecutivo, en concreto, el incumplimiento por parte de las autoridades de las sentencias del TC que declaraban la invalidez del mandato de los jueces referidos, socava la exigencia de que el tribunal sea establecido por la ley para proteger al poder judicial de influencias externas ilegales. Así, el TEDH recuerda que el derecho "a un tribunal establecido por la ley" es un reflejo del principio de legalidad en sí mismo y juega un importante papel en el mantenimiento de la separación de poderes y la independencia y legitimidad del poder judicial, como exige una sociedad democrática, en línea con lo argumentado en la sentencia recaída en el caso Guðmundur Andri Ástrádsson c. Islandia, antes citada (parágrafo 281).

El TEDH continúa indicando que uno de los aspectos fundamentales del principio de legalidad es el principio de seguridad jurídica, que exige, entre otras cosas, que no se deberían poner en cuestión las sentencias definitivas de los tribunales. En este caso, el poder legislativo y el ejecutivo han incumplido su deber de respetar las sentencias del TC que resolvieron la polémica de la elección de sus magistrados por lo que sus acciones fueron incompatibles con el principio de legalidad. De hecho, pretendieron usurpar el papel del TC como intérprete último de la Constitución y de la constitucionalidad de las leyes.

Por consiguiente, el TEDH considera que se ha violado el derecho de la demandante a un "tribunal establecido por la ley" (art. 6.1 CEDH).

El TEDH, por consiguiente, resuelve en las sentencias recaídas en los casos Reczkowicz c. Polonia, de 22 de julio de 2021, y Xero Flor W Polsce sp. z o.o c. Polonia, de 7 de mayo de 2021, que las inmisiones de los poderes ejecutivo y legislativo en el poder judicial, que infringen lo establecido por la ley, son contrarias al Convenio Europeo de Derechos Humanos.

\section{DERECHO A UN PROCESO EQUITATIVO (II): DERECHO A RECURRIR UNA DECISIÓN ADMINISTRATIVA ANTE UN TRIBUNAL}

En la sentencia recaída en el caso Loquifer c. Bélgica, de 20 de julio de 2021, la demandante se jubiló anticipadamente tras ejercer como juez durante veinte años. Fue nombrada miembro "no judicial" del Consejo Superior de la Judicatura (CSJ) a propuesta del Senado.

La demandante fue imputada por delitos de falsificación y uso de documentos falsos por actos presuntamente cometidos en su condición de presidenta del Tribunal de Primera Instancia de Nivelles. 
El CSJ la suspendió de todos sus cargos por un periodo renovable de seis meses. La medida tenía efecto inmediato. No obstante, podía revocarse si la Fiscalía de Bruselas decidía desimputarla. La medida de suspensión fue renovada varias veces hasta que se dictara la sentencia penal.

El tribunal de apelación de Bruselas la citó a comparecer por las imputaciones. Fue absuelta. Posteriormente, solicitó al CSJ que revisara la decisión por la que la suspendía de todos sus cargos.

En una reunión general del CSJ, celebrada el 25 de marzo de 2015, se tomó en cuenta la decisión final de absolución de la demandante en el proceso penal y observó que cumplía los criterios para su reincorporación. La demandante, sin embargo, renunció a su cargo en el CSJ. Criticó la actitud que el CSJ había adoptado hacía ella. A su modo de ver, había dañado su honor.

La demandante acude ante al TEDH alegando una violación del art. 6.1 CEDH. Dice que la sanción disciplinaria fue impuesta por un órgano no judicial y que no ha dispuesto de un medio de impugnación para atacarla. La demandante también dice que no ha disfrutado del derecho de audiencia y que no se le permitió el acceso a la asamblea general del CSJ.

El TEDH observa que, de conformidad con el derecho interno, el CSJ es un órgano administrativo. Como su función no es la de dilucidar disputas, no constituye un tribunal en el sentido del art. 6.1 CEDH.

A este respecto, el TEDH recuerda que, si un órgano resuelve conflictos, pero no cumple los criterios que debe reunir un tribunal en el sentido del art. 6.1 $\mathrm{CEDH}$, debe haber un control judicial posterior que reúna todas las garantías del art. 6.1 CEDH. De conformidad con las normas consolidadas del Consejo de Estado, la recurrente, como miembro del CSJ, no podía recurrir la decisión controvertida. A modo de ver del TEDH, el Gobierno no probó que existiera un medio de impugnación que permitiera a la demandante revisar la decisión por la que se le suspendió en el ejercicio de sus cargos del CSJ. Por tanto, la decisión de suspensión no ha sido adoptada por un "tribunal" u otro órgano que ejerza poderes judiciales y no estaba sujeta a revisión judicial. Por ello, la demandante ha sido privada de su derecho de acceso a un tribunal con la finalidad de recurrir la medida, por lo que concluye que ha habido una violación del art. 6 del Convenio.

A modo de ver del TEDH, el resto de alegaciones de la demandante sobre la violación de su derecho de audiencia y la denegación de su acceso a la asamblea general están vinculadas a la demanda principal, con lo que el TEDH considera innecesario examinarlas separadamente.

\section{DERECHO A UN PROCESO EQUITATIVO (III): ARBITRARIEDAD EN LA ADMISIÓN DEL RECURSO DE CASACIÓN}

En la sentencia recaída en el caso Inmobilizados y gestiones S.L. c. España, de 14 de septiembre de 2021, el Ayuntamiento de San Lorenzo de El Escorial 
expropió cinco solares de una misma propiedad. La propietaria, Inmobilizados y gestiones S.L., recurrió los justiprecios ante la jurisdicción contencioso-administrativa. El TSJ de Madrid desestimó los recursos interpuestos. La demandante, entonces, interpuso, en fechas diferentes, cinco recursos de casación contencioso-administrativos del régimen anterior a la reforma de la Ley Orgánica 7/2015, de 21 de julio, por la que se modifica la Ley Orgánica 6/1985, de 1 de julio, del Poder Judicial. Los cinco recursos eran sustancialmente idénticos en cuanto a las alegaciones, basadas en tres motivos diferentes. El Tribunal Supremo inadmitió tres de los recursos presentados. Admitió y estimó los restantes. La demandante recurrió en amparo. El TC inadmitió porque consideró que el asunto carecía de trascendencia constitucional.

El TEDH comenzará su argumentación recordando los principios generales en relación con el formalismo excesivo en la admisión de los recursos, establecidos en las SSTEDH recaídas en los casos Zubac c. Croacia, de 5 de abril de 2018, y Gil Sanjuan c España, de 26 de mayo de 2020.

El formalismo excesivo, dice el TEDH, puede ir contra la exigencia de asegurar un derecho real y efectivo de acceso a un tribunal, en base al art. 6.1 $\mathrm{CEDH}$. Ello ocurre en casos en los que se construye una regla procesal especialmente estricta que impide el examen del recurso del demandante sobre el fondo, con el riesgo de que se infrinja el derecho a una protección efectiva de los tribunales. Cuando el demandante alega que se ha dado un formalismo excesivo en la admisión de su asunto, el TEDH analizará el caso en su conjunto teniendo en cuenta los principios de seguridad jurídica y de buena administración de justicia, que considera dos elementos centrales para delimitar una distinción entre el formalismo excesivo y una aplicación aceptable de las formalidades procesales. En concreto, en el asunto Gil Sanjuan dijo que el derecho de acceso a un tribunal se socava cuando las reglas dejan de servir a las finalidades del principio de seguridad jurídica y forman una suerte de barrera que impiden al litigante el conocimiento de su caso sobre el fondo por el tribunal competente.

El TEDH recuerda, más específicamente, que uno de los aspectos fundamentales del principio de legalidad es el principio de seguridad jurídica, un principio implícito en el Convenio, como dijo en la sentencia recaída en el caso Beian c. Rumanía $N^{o} 1$, de 6 de diciembre de 2007. Las decisiones contradictorias en casos similares que proceden del mismo tribunal que, además, es el tribunal de última instancia, pueden violar ese principio y, por consiguiente, menoscabar la confianza de los ciudadanos en el poder judicial, como ha dicho en las sentencias recaídas en los casos Beian, antes citado, Tudor Tudor c. Rumanía, de 29 de marzo de 2009, e Iordan y Iordanov y otros c. Bulgaria, de 2 de julio de 2009. Dicha confianza es uno de los componentes esenciales de un Estado basado en el principio de legalidad, como dijo en el asunto Vusić c. Croacia, de 1 de julio de 2010. En este sentido, el TEDH recuerda que las decisiones diferentes de los tribunales internos basadas en hechos idénticos son susceptibles de ir contra el principio de seguridad jurídica y pueden implicar una denegación de justicia (véase, en 
este sentido, la sentencia Santos Pinto c. Portugal, de 20 de mayo de 2008). El TEDH dijo en ese caso que se violó el art. 6.1 del Convenio ya que la divergencia del examen del tribunal de apelación en situaciones idénticas tuvo el efecto de la privación del demandante de la posibilidad de someter sus alegaciones al conocimiento del tribunal en uno de los casos, referido a un solar, examinados por el tribunal superior, mientras que sí lo pudo hacer en el proceso en relación con otro solar.

El TEDH recuerda también que su función es el examen de la compatibilidad con el convenio de los efectos de la interpretación de las normas aplicadas, lo cual es especialmente importante en cuanto a las normas procesales, ya que inciden en mayor medida en los principios de seguridad jurídica y buena administración de justicia.

Este caso, sin embargo, no versa sobre las formalidades en el acceso a la casación, sino que las alegaciones de la demanda se articulan en torno a la arbitrariedad del Tribunal Supremo al admitir y estimar recursos de casación, como ya tuvo ocasión de conocer en la reciente sentencia Gilsanjuan c. España, antes citada, en la que el TEDH resuelve que la aplicación retroactiva de nuevas exigencias jurisprudenciales en la preparación del recurso a demandas interpuestas antes del cambio jurisprudencial, no se ajustaba al derecho a un proceso equitativo (art. $6 \mathrm{CEDH})^{4}$. En el presente caso, en concreto, la demandante dice que el TS ha ofrecido decisiones contradictorias, sin una justificación razonable, en cuanto a la admisión de cinco recursos de casación en relación con el mismo problema legal y que afectaban a las mismas partes del proceso.

El TEDH observa que el TS, con el mismo magistrado actuando como ponente en el proceso de admisión de los cinco recursos de casación planteados por la misma demandante, ha dictado diferentes pronunciamientos. Dos de los

\footnotetext{
Al respecto, véanse los trabajos de Carmen Chinchilla Marín (2020), "Nadie puede ser privado del derecho al recurso por incumplir un requisito que no era exigible en el momento de su presentación (comentario a la Sentencia del TEDH de 26 de mayo de 2020, caso Gil Sanjuán contra España)", RAP 213, 263-296; Carmen Chinchilla Marín (2011), "Nuevos criterios para la admisión del recurso de casación contra sentencias y autos de la Audiencia Nacional", Justicia Administrativa: Revista de Derecho Administrativo 52, 25-50; Omar Bouazza Ariño (2020), "Retroactividad in peius de nuevas exigencias en la preparación del recurso de casación. Su sanción por el Tribunal Europeo de Derechos Humanos (Nota a la STEDH Gil Sanjuán c. España, de 26 de mayo de 2020), RGDA 55, 6 p. La problemática que plantea esa línea jurisprudencial del TS fue denunciada previamente a la sentencia de Estrasburgo, en los trabajos de Omar Bouazza Ariño (2013), El recurso de casación contencioso-administrativo común. Estudio de legislación y de jurisprudencia y propuestas para su reforma, Cizur Menor: Civitas, págs. 146 y ss.; José Ramón Rodríguez Carbajo (2013), "La aplicación retroactiva de la nueva doctrina del Tribunal Supremo sobre el escrito de preparación", Actualidad Administrativa, 1; José Ramón Rodríguez Carbajo (2015), "Los diversos escritos preparatorios del recurso de casación (II)", Actualidad Administrativa, 4.
} 
recursos fueron admitidos mientras que los tres restantes se inadmitieron por su defectuosa preparación. El TEDH constata que los recursos que fueron admitidos por la sección de admisión serían estimados.

El TEDH subraya que los cinco recursos se refieren al proceso de expropiación entablado contra los cinco solares de la demandante que se encuentran en la misma finca, afectaban a las mismas partes del proceso y estaban fundamentados en las mismas normas.

El TEDH no encuentra una justificación razonable a las diferentes conclusiones arribadas por el TS para la admisión de los asuntos. El TS no ofreció ninguna razón que justificara estas decisiones contradictorias. Incluso las acciones de nulidad de actuaciones interpuestas por la demandante ante el TS, solicitando la rectificación de las decisiones a la vista de los cinco recursos considerados conjuntamente, fueron desestimadas.

El TEDH subraya que las tres inadmisiones no solo han impedido que el TS conociera su caso en cuanto al fondo, sino que no ha contribuido a crear seguridad jurídica en cuanto a los requisitos de acceso a la casación. La divergencia en la solución ofrecida por el TS a situaciones sustancialmente iguales ha privado a la demandante de la posibilidad de que el Alto Tribunal examinara tres de sus recursos, mientras que sí ha sido posible en relación con los otros dos recursos.

Por todo ello, el TEDH considera que la diferencia injustificada en la aplicación de criterios de admisibilidad en los anteriores recursos ha privado a la demandante de su derecho de acceso al TS, por lo que ha habido una violación del art. 6.1 CEDH.

\section{DERECHO AL RESPETO DE LA VIDA PRIVADA Y FAMILIAR: DIGNIDAD DEL CUERPO HUMANO TRAS LA MUERTE Y LIBERTAD DE INVESTIGACIÓN CIENTIIFICA}

En la sentencia recaída en el caso Polat c. Austria, de 20 de julio de 2021, el hijo de la demandante nació prematuramente y falleció dos días después. Padecía una enfermedad rara por lo que los médicos que le trataron decidieron que era necesario un análisis post mortem para clarificar el diagnóstico. La demandante y su marido rechazaron tal decisión por razones religiosas y explicaron que deseaban enterrar a su hijo de conformidad con el rito musulmán, que requiere que el cuerpo permanezca lo más indemne posible. A pesar de sus objeciones, se realizó la autopsia y prácticamente se retiraron todos los órganos del bebé. La demandante no fue informada del alcance de la autopsia y creía que podría enterrar a su hijo. Se dio cuenta del aspecto del cuerpo durante el funeral, que se celebró en su pueblo natal en Turquía. En efecto, en la ceremonia, en la que estaban presentes más de 100 invitados, el cuerpo del niño fue desvestido por la persona religiosa que dirige el acto (Hodja) y la demandante. Las dos mujeres se dieron cuenta de que se habían retirado los órganos del niño. Los genitales no eran 
reconocibles. El cuerpo se encontraba en mal estado ya que había comenzado el proceso de descomposición. La imagen causó un fuerte impacto emocional a la madre. Como los genitales del bebé no eran reconocibles, se suspendió el ritual, que varía en función de si se trata de un niño o de una niña. La demandante recurrió sin éxito en la vía interna.

Ante el TEDH, la demandante alega una violación de los arts. 8 y 9 CEDH debido a que se realizó una autopsia al bebé a pesar de la disconformidad de la madre.

El TEDH considera que ha habido una interferencia, contemplada en la ley interna, en el derecho de la demandante a su vida privada y familiar, así como a su derecho a manifestar su religión. El derecho a la vida privada y familiar, dice el TEDH, puede extenderse a ciertas situaciones después de la muerte, como dijo en la sentencia recaída en el caso Elberte c. Letonia, de 13 de enero de 2015. Por otro lado, la autopsia se ha realizado para la salvaguarda de los intereses científicos y servía la finalidad legítima de la protección de la salud de los demás. En relación con la proporcionalidad de la medida, el TEDH observa que el caso se refiere a la regulación de las autopsias en los hospitales públicos y la cuestión de si se debe reconocer - y en qué casos- el derecho de los familiares a oponerse a una autopsia por razones referidas a la vida privada y la religión en los casos en los que las razones de salud pública claramente aconsejan la medida. A este respecto, los Estados contratantes tienen la obligación positiva, en base al art. $8 \mathrm{CEDH}$, de adoptar las medidas apropiadas para proteger la salud de aquellos que se encuentran en su jurisdicción. El margen de apreciación del Estado, por tanto, es amplio.

El TEDH considera que no pueden cuestionarse las consideraciones del médico que practicó la autopsia, que asegura que el examen se realizó respetando la lex artis. Por otro lado, el derecho interno no reconoce el derecho a oponerse a una autopsia por parte de los familiares en base a razones religiosas. Los derechos contenidos en los arts. 8 y $9 \mathrm{CEDH}$, recuerda el TEDH, no son absolutos.

Aunque el derecho interno no ofrece a las autoridades la potestad de realizar autopsias en todo caso, el legislador austriaco ha elegido dar preferencia a los intereses de la salud de los demás frente a razones religiosas o de otro tipo de los familiares de la persona fallecida en casos de necesidad de salvaguarda de los intereses cientificos, especialmente si un caso no ha tenido un diagnóstico claro. El TEDH tiene en cuenta las alegaciones del Gobierno en virtud de las cuales este tipo de exámenes post mortem tienen una importancia fundamental en el avance de la medicina moderna, así como en la larga y cuidada tradición del derecho de autopsias en Austria, que se percibe como una parte integral de la libertad de ciencia garantizada constitucionalmente ${ }^{5}$, un derecho íntimamente vinculado a las obligaciones positivas derivadas de los arts. 2 y 8 de adoptar medidas apropiadas para proteger

5 Sobre este tema, me remito al libro de Antonio Eduardo Embid Tello (2017), La libertad de investigación cientifica. Una interpretación integrada de sus dimensiones subjetiva y objeti$v a$, Valencia: Tirant lo Blanch. 
la vida de los demás a través de los exámenes post mortem de los cadáveres que se encuentran bajo su jurisdicción. Al mismo tiempo, el TEDH es consciente de la relevancia en el contexto de los intereses de la demandante de asegurar que los restos de su hijo fallecido fueran respetados con la finalidad de la celebración de la ceremonia del funeral, una preocupación que expresó desde el principio.

Teniendo en cuenta las pruebas practicadas en el proceso en la vía interna, el TEDH considera, en línea con los tribunales internos, que había un interés científico en la realización del examen post mortem. No obstante, el TEDH observa que el derecho interno ofrece a los médicos cierto margen de discreción atendiendo a las circunstancias concurrentes en cada caso, así como el alcance de la intervención. No excluye, por tanto, que se realice una ponderación de los derechos e intereses concurrentes. Sin embargo, las razones ofrecidas por la demandante no fueron valoradas por el personal del hospital. Tampoco las tuvo en cuenta el tribunal de apelación, al decidir la acción de indemnización, ni el Tribunal Supremo.

En consecuencia, el TEDH decide que, si bien en este caso las autoridades internas disponían de un amplio margen de apreciación, no se ha llevado a cabo una ponderación justa de los intereses concurrentes, esto es, los requerimientos de salud pública con respecto del derecho al respeto de la vida privada y familiar de la demandante, así como su interés de enterrar a su hijo de conformidad con sus creencias religiosas. Por todo ello, concluye que ha habido una violación de los arts. 8 y 9 CEDH.

\section{LIBERTAD DE EXPRESIÓN}

\section{BANDERAS REIVINDICATIVAS}

En la sentencia recaída en el caso Tökés c. Rumanía, de 27 de abril de 2021, el demandante es un ciudadano rumano que pertenece a los sículos, minoría húngara de Rumanía presente principalmente en Transilvania (País Sículo). Vive en Oradea (Rumanía), ciudad que se encuentra cerca de la frontera con Hungría. Fue elegido como miembro del Parlamento Europeo en la lista de la Unión Democrática de Húngaros en Rumanía en las elecciones europeas de 2009. Formó parte de la lista del partido húngaro Fidesz en las europeas de 2014. En el momento de los hechos tenía un despacho en Oradea.

En su primera demanda, el demandante dice que el 18 de junio de 2014 puso una bandera de los sículos de dos metros y medio en la fachada del edificio de su oficina en Oradea. La policía local le impuso una sanción leve en la forma de apercibimiento el 20 de agosto de 2014. La policía motivó la sanción en que se había desplegado la bandera con fines publicitarios sin solicitar la preceptiva autorización, según exige la Ley 185/2013, sobre ubicación de elementos publicitarios. Se requirió al demandante a que retirara la bandera. Recurrió la sanción ante el tribunal de primera instancia de Oradea, órgano judicial que desestimaría 
su demanda. El demandante recurrió esta sentencia y en una sentencia final el tribunal de distrito de Bihor desestimó la apelación el 27 de noviembre de 2015 y ratificó el razonamiento de la sentencia de primera instancia. Según el tribunal, el demandante enarboló la bandera, que incluía símbolos de los sículos, con la finalidad de llamar la atención de los ciudadanos sobre el uso que se estaba haciendo del espacio en cuestión, por lo que la bandera se habría utilizado con fines publicitarios tal y como se definen por la ley citada. El tribunal dejó claro que enarbolar una bandera como la de los sículos en público, aunque en un edificio de propiedad privada, no estaba prohibido por la ley. No obstante, debe realizarse según las normas vigentes, como las que exigen la obtención de una licencia con fines publicitarios.

En una segunda demanda, el demandante dijo que en diciembre de 2015 puso una bandera del territorio histórico de Partium en el edificio de su oficina, una bandera blanca que lleva una doble cruz y cuatro líneas rojas que representan los cuatro ríos que discurren por la región. La bandera se puso junto con otras, como la bandera de los sículos, la bandera nacional de Rumanía, la bandera nacional de Hungría y la bandera de la Unión Europea. La policía le impuso una sanción leve, a modo de apercibimiento, y le requirió su retirada.

El demandante recurrió la sanción. Dijo que pasaba la mayor parte del tiempo en Estrasburgo y en Luxemburgo y que había alquilado un despacho en Oradea para la duración de su mandato. El tribunal de primera instancia desestimó el recurso. Consideró que la bandera del territorio de Partium, así como la de los sículos, no son banderas que pertenezcan a un Estado reconocido. El tribunal sostuvo que al desplegar las banderas el demandante intentó llamar la atención de los ciudadanos con la finalidad de informar sobre actividades y actos. La bandera debía ser considerada por tanto como "material de publicidad". Según el tribunal, enarbolar la bandera de los sículos en público, incluso en edificios de propiedad privada, está regulado por la Ley 185/2013, que exige la obtención de una licencia.

El demandante recurriría, asimismo, esta decisión, sin éxito.

El 24 de febrero de 2020, tras una inspección policial, el demandante retiró las banderas.

Concluida la vía interna, el demandante acude ante el TEDH alegando una violación del art. $10 \mathrm{CEDH}$ (libertad de expresión). Dice que las amonestaciones por poner las banderas del País Sículo y del territorio Partium en el edificio del despacho en el que trabajaba en Oradea infringieron su libertad de expresión.

El TEDH observa que el demandante ha sido sancionado por desplegar la bandera de los sículos y del territorio histórico de Partium ya que no solicitó la licencia de publicidad contemplada en la ley. La sanción estaba prevista en la Ley 185/2013. El TEDH, a continuación, examina si la medida perseguía un fin legítimo y era necesaria en una sociedad democrática.

El TEDH observa que la finalidad a la que se refiere el Gobierno para la justificación de las medidas en cuestión es el aseguramiento de la seguridad 
pública y el respeto de los derechos de los demás. La Ley 185 pretende, según su art. 1, asegurar que el medio ambiente construido es coherente, armonioso, seguro y saludable, con la finalidad de proteger el patrimonio natural y construido, preservar la calidad del paisaje conforme con los estándares exigidos en términos de calidad de la edificación. El caso plantea, por tanto, una concurrencia de intereses en conflicto: la libertad de expresión del demandante y la protección de los derechos de los demás en el contexto de la Ley 185/2013, aplicable en este caso.

Al examinar si la interferencia fue necesaria en una sociedad democrática, el TEDH presta atención a las decisiones de los tribunales internos. A este respecto, observa que los tribunales no han tenido en consideración el contexto de las quejas del demandante, esto es, que las sanciones impuestas han interferido en su libertad de expresión, en el sentido del art. $10 \mathrm{CEDH}$. El TEDH comprueba que, al determinar la ley aplicable, han considerado que las banderas en cuestión debían ser entendidas como una forma de publicidad. No explicaron por qué rechazaron las alegaciones de los demandantes de que las banderas no tenían como finalidad la promoción de sus actividades, sino que han sido simplemente un medio para expresar su propia identidad. El TEDH observa que algunas de las definiciones de la noción de publicidad contenidas en el art. 3 (o) de la Ley 185/2013 están íntimamente vinculadas con actividades comerciales en general. Las autoridades debían ofrecer razones para desestimar los argumentos del demandante, en la medida en que la noción de publicidad en el derecho interno se definía en términos amplios y que las autoridades nacionales tenían un margen de discrecionalidad al decidir las banderas que debían considerarse como materiales de publicidad.

El TEDH subraya que hay que distinguir los mensajes comerciales de aquellos que contribuyen a un debate público en materias de interés general. En el presente caso, al clasificar las banderas en cuestión como materiales de publicidad, los tribunales internos no han examinado su contenido, no han ofrecido ningún ejemplo de actos o actividades que supuestamente anunciaban las banderas. Tal examen revestía especial importancia en este caso en la medida en la que la bandera de los sículos evoca temas importantes en el seno de la sociedad rumana en línea con la cuestión de interés general referida a la autonomía de los territorios habitados por la minoría húngara.

A modo de ver del TEDH, las autoridades no han explicado con suficiente detalle su decisión de clasificar las banderas como materiales de publicidad.

El TEDH además observa que los tribunales internos no han examinado si el sitio en el que el demandante ha colgado la bandera, su oficina parlamentaria, debe ser un factor importante en el caso. Los tribunales internos tampoco han tenido en cuenta el estatus del demandante de diputado del Parlamento Europeo o los derechos que derivan de ese estatus. En concreto, no han establecido con certeza si el demandante pretendía actuar como político que presenta un programa político o como un ciudadano ordinario que 
pertenece a una minoría nacional que desea manifestar su pertenencia a esa minoría. El TEDH también observa que en el momento en el que se produjeron los hechos el demandante era miembro del Parlamento Europeo como miembro de un partido húngaro, en lugar de rumano, y por consiguiente, era representante de la mayoría húngara en Hungría, en lugar de la minoría húngara en Rumanía. El TEDH considera que estos elementos son importantes para determinar la naturaleza del discurso en cuestión. Los tribunales, según el TEDH, no debieron ignorarlos.

Como los tribunales internos no examinaron todas las pruebas presentadas, no han podido determinar, a la luz del criterio definido y aplicado por el TEDH en casos sobre libertad de expresión, la naturaleza del mensaje que el demandante ha querido transmitir y el contexto en el que debe situarse el discurso.

En relación con las cuestiones referidas a la seguridad pública y la protección de los derechos de los demás, sugeridas por el Gobierno, el TEDH subraya que los tribunales internos no han justificado en qué sentido las banderas podían implicar cuestiones de seguridad pública. Es más, enarbolar las banderas no está prohibido, pero debe realizarse de conformidad con las normas de publicidad. El TEDH también observa que la bandera del territorio histórico de Partium se puso junto con otras banderas. Los tribunales internos no han explicado por qué solo esa bandera, y no las otras, está sujeta a una autorización previa de publicidad de conformidad con la legislación diseńada para asegurar que el patrimonio construido es coherente, harmonioso y seguro, con la finalidad de proteger la calidad del paisaje conforme con los estándares exigidos en términos de calidad de la edificación. A mayor abundamiento, el demandante fue sancionado en junio de 2014 y diciembre de 2015. No obstante, no se le requirió la retirada de las banderas hasta el 24 de febrero de 2020 . No hay nada en el expediente que indique que, durante este periodo de varios años, las banderas hayan causado problemas a las autoridades en términos de seguridad medioambiental.

Finalmente, el hecho de que la sanción haya sido leve no compensa que no se hayan ofrecido razones suficientes y relevantes para restringir la libertad de expresión. Los tribunales internos no han tenido en cuenta la jurisprudencia del TEDH sobre este tema y no han aportado razones suficientes y pertinentes para justificar la interferencia en la libertad de expresión del demandante. Por ello, el TEDH considera que la injerencia litigiosa no ha sido necesaria en una sociedad democrática. Por tanto, el TEDH decide por cinco votos contra dos que ha habido una violación del art. $10 \mathrm{CEDH}^{6}$.

6 La juez rumana, Iulia Antoanella Motoc, y la austriaca, Gabriele Kucsko-Stadlmayer, presentaron una opinión disidente común en la que rebaten la decisión mayoritaria por razones de congruencia, entre otras. Me remito a la lectura de la sentencia para averiguar su contenido. 


\section{REDES SOCIALES Y DISCURSO XENÓFOBO. EL GESTOR DE LA CUENTA ES RESPONSABLE DE LOS COMENTARIOS DE SUS SEGUIDORES}

Julien Sánchez es el alcalde del municipio occitano de Beaucaire por la formación de extrema derecha, Agrupación Nacional (Rassemblement National). En 2011, cuando era candidato al Parlamento por la formación predecesora, el Frente Nacional (Front National), por la circunscripción de Nîmes, puso un mensaje en su muro de la red social Facebook, cuyo acceso estaba abierto para todo el mundo, y que gestionaba él mismo. El mensaje se dirigía a F. P., diputado por la UMP (Union pour un mouvement populaire), en el que alardeaba de que el partido de extrema derecha ofrecía a sus simpatizantes una nueva página web, mientras que la UMP había incumplido, al parecer, la previsión de inauguración de la suya para ese mismo día. Este mensaje aparentemente anodino sirvió para que los amigos del alcalde del Frente Nacional escribieran mensajes xenófobos. Por ejemplo, S. B. escribió: "Este gran hombre ha transformado Nîmes en Argelia, no hay ninguna calle en la que no haya un kebab y una mezquita; el reino supremo de los camellos y las prostitutas. No sorprende que eligiera Bruselas, capital del nuevo orden de la sharía [...]", refiriéndose además a L. T., pareja del diputado de la UMP, de origen árabe. Otro usuario, L. R., añadió varios mensajes dirigidos a la comunidad musulmana del país.

L. T. conocía a S. B. Al día siguiente de publicación de los comentarios, la primera se dirigió a la peluquería de la segunda, al sentirse insultada directamente. S. B. eliminó el mensaje inmediatamente.

Dos días después de la publicación del mensaje original que dio pie a estos mensajes xenófobos, L. T. interpuso una querella criminal contra el alcalde por los comentarios ofensivos publicados en su muro. Pocas horas después, el señor Sánchez publicó un nuevo mensaje invitando a sus amigos a "controlar el contenido de sus mensajes", pero no intervino en relación con los comentarios que ya se habían publicado.

El alcalde, S. B. y L. R. fueron citados a comparecer ante el tribunal penal de Nîmes en relación con la publicación de los comentarios en cuestión. Fueron imputados por incitación al odio o la violencia contra un grupo de personas y, en concreto, contra L. R., por razón de su origen o su pertenencia a un grupo étnico específico, nacionalidad, raza o religión. El tribunal penal condenó a los tres imputados a pagar una multa de 4.000 euros y, además, condenó al demandante y a S. B. a pagar a L.T. 1.000 euros en concepto de daño moral. Como el demandante gestionaba directamente su cuenta de Facebook con la finalidad de intercambiar opiniones y al dejar los comentarios ofensivos varias semanas y no actuar rápidamente contra la diseminación de dichos mensajes era culpable como responsable de su perfil y, por consiguiente, como el autor principal de la agresión. El tribunal de apelación confirmó la decisión de primera instancia, reduciendo en 1.000 euros la sanción principal. Dijo que el alcalde, como configuró su cuenta de Facebook abierta a todo el mundo, asumió la responsabilidad 
del contenido de los comentarios publicados y que su estatus de político requiere una mayor vigilancia por su parte. El tribunal de casación desestimó su recurso.

No parece que el alcalde tenga excesiva confianza en los tribunales internos franceses ${ }^{7}$. Quizá pensaría que en Estrasburgo encontraría amparo a su discurso ilegal, por lo que acude ante esta sede alegando una violación de su derecho a la libertad de expresión (art. $10 \mathrm{CEDH}$ ). Al parecer, no se hacía responsable de los comentarios de sus amigos.

En la sentencia recaída en el caso Sanchez c. Francia, de 2 de septiembre de 2021, el TEDH, en primer lugar, asume la argumentación ofrecida por los tribunales internos para fundamentar la condena del demandante, subrayando su responsabilidad como gestor personal de su cuenta en la red social.

En cuanto a la naturaleza de los comentarios, el TEDH subraya que son claramente ilegales. Tanto el tribunal de primera instancia como el de apelación han dicho que los comentarios definen al grupo de personas afectadas, los que profesan la fe musulmana, y que la asociación de la comunidad musulmana con el delito y la inseguridad en la ciudad de Nîmes al equipararla con la prostitución, los traficantes de droga, los que "tiran piedras a los coches", etc., eran susceptibles de generar un sentimiento fuerte de rechazo y hostilidad hacia los musulmanes. Además, las referencias a la pareja del diputado de la UMP, de origen árabe, le han vinculado directamente con la transformación de la ciudad, lo que ha generado odio y violencia hacia ella.

El TEDH subraya que la tolerancia y el respeto de la dignidad de todos los seres humanos en condiciones de igualdad constituye uno de los fundamentos de la sociedad democrática y pluralista. El TEDH, en este sentido, argumenta que es necesario castigar o prevenir todas las formas de expresión que diseminan, incitan, promueven o justifican el odio basado en la intolerancia, en el bien entendido de que todas las formalidades, condiciones, restricciones o sanciones sean proporcionadas a la finalidad legítima perseguida.

Si bien en un contexto electoral los políticos gozan de una amplia libertad de expresión, tienen una especial responsabilidad en la lucha contra el discurso del odio, en línea con lo establecido en la Recomendación del Consejo de Europa R(97)20 sobre "discurso del odio" y la Comisión Europea contra el Racismo y la Intolerancia ${ }^{8}$.

7 Más bien, a pesar de la condena penal, ha seguido enviando mensajes similares en otras redes sociales como Youtube. Me refiero a un vídeo colgado el 11 de septiembre de 2017 que, a 30 de septiembre de 2021, tiene 14.939 visualizaciones. Omito deliberadamente compartir aquí el enlace.

8 El Tribunal Europeo de Derechos Humanos, especialmente en los temas de mayor gravedad, suele apoyar sus razonamientos en normas de soft law de los organismos especializados del Consejo de Europa, a modo de refuerzo de la decisión adoptada en base a los preceptos del CEDH y de sus protocolos adicionales. Ha estudiado este tema, en relación con el Comité de Prevención de la Tortura, el profesor de la Universidad Complutense, 
El TEDH considera, en línea con lo decidido en el ámbito interno, que las conclusiones alcanzadas por los tribunales internos están justificadas. El lenguaje utilizado ha incitado al odio y la violencia. A modo de ver del TEDH, los ataques personales mediante insultos, la ridiculización o la difamación dirigida a ciertos grupos de población, o la incitación al odio y la violencia contra una persona en base a su pertenencia a una religión en particular, es suficiente para que las autoridades lo asumieran como una cuestión prioritaria para combatir ese comportamiento que implica un ejercicio irresponsable de la libertad de expresión que menoscaba la dignidad, e incluso la seguridad, de los grupos de población víctimas de los ataques.

En relación con la responsabilidad del demandante por las declaraciones publicadas por terceros, el TEDH observa que los comentarios debían contextualizarse en el debate político local en relación con una campaña electoral parlamentaria. El TEDH recuerda que, si bien el margen de la libertad de expresión en el ámbito de lo político debe ser muy amplio, las declaraciones que se han dado en este caso son claramente ilegales, contrarias, además, a las normas de uso de la red social. Es más, el demandante no ha sido condenado por el ejercicio de su libertad de expresión en el contexto del debate político, sino que ha sido condenado por su falta de vigilancia y capacidad de respuesta en relación con los comentarios colgados en el muro de su cuenta de Facebook. El demandante, dice el TEDH, debía controlar cuidadosamente el contenido de cada mensaje que colgaban sus seguidores. Como dijo el tribunal de apelación, se le exige una mayor responsabilidad en este sentido por su condición de político. El TEDH tiene en cuenta además que los mensajes han estado visibles unas seis semanas.

El TEDH, por consiguiente, concluye que los tribunales internos han basado sus decisiones en relación con la responsabilidad del demandante en razones relevantes y suficientes a los efectos del art. 10 del Convenio. La sanción impuesta, además, no ha sido desproporcionada. En fin, el TEDH considera que las decisiones de los tribunales internos de condena al demandante por no eliminar rápidamente los comentarios ilegales colgados por otras personas en su muro de Facebook, que fueron usados en relación con su campaña electoral, se han basado en razones suficientes y relevantes, teniendo en cuenta el margen de apreciación del Estado. Por tanto, cada uno es responsable de los comentarios que se cuelgan en sus perfiles de redes sociales, especialmente en el caso de los políticos, a los que se les exige una mayor responsabilidad y cuidado en la lucha contra la propagación de discursos ilegales de carácter xenófobo, lo cual es especialmente grave si el político se apoya en esos mensajes para impulsar su campaña electoral. Por todo ello, el TEDH considera que la interferencia en la libertad de expresión del alcalde era necesaria en una sociedad democrática, por lo que no ha habido una violación del art. $10 \mathrm{CEDH}$.

Ignacio Álvarez Rodríguez (2021), Diálogos metajudiciales en Estrasburgo, Cizur Menor (Navarra): Thomson-Aranzadi. 


\section{SANCIONES DISCIPLINARIAS}

En las sentencias recaídas en los casos Sedat Doğan c. Turquía, Naki y Amed Sportif Faaliyetler Kulübü Derneği c. Turquia e Ibrahim Tokmak c. Turquía, de 18 de mayo de 2021, la Federación turca de fútbol impuso sanciones deportivas y pecuniarias a los demandantes por sus declaraciones en redes sociales y medios de comunicación.

\section{Asunto Sedat Doğan}

En el momento de producirse los hechos, el demandante formaba parte del consejo de administración del club de fútbol Galatasaray.

En una conversación telefónica criticó la decisión de la comisión de disciplina de fútbol profesional de denunciar ante la federación turca de fútbol a dos de los jugadores de su equipo que portaban camisetas en homenaje a Nelson Mandela, fallecido el día anterior.

La comisión de disciplina consideró que sus comentarios antideportivos eran constitutivos de una infracción por lo que le impuso una sanción disciplinaria ligada al ejercicio de sus funciones durante sesenta días y una multa de 44.000 libras turcas. El comité de arbitraje confirmó esa decisión.

El demandante, a raíz de la sanción impuesta, publicó varios mensajes en su cuenta de Twitter, con el hashtag \#Adiós Federación turca de fútbol y otros mensajes. La comisión de disciplina le impuso nuevas sanciones de suspensión en el ejercicio de sus funciones y económicas, al considerar que los textos tenían una naturaleza antideportiva, que desvalorizaban la imagen del fútbol, incitaban a la violencia y al desorden y a las protestas de los aficionados.

La comisión de arbitraje confirmó esta decisión el 26 de diciembre de 2013. Asunto Naki y Amed Sportif Faaliyetler Kulübü Derneği

Los demandantes son un futbolista profesional y el club en el que jugaba en el momento en el que se produjeron los hechos, que se encontraba en la primera liga del campeonato profesional turco (Süper Lig).

El señor Naki publicó un mensaje en su cuenta de Facebook el 21 de enero de 2016, tras la victoria de su equipo en un campeonato de la Super Liga. El 4 de febrero de 2016, la comisión de disciplina de fútbol profesional consideró que las expresiones del demandante tenían un carácter ideológico, menoscababan la imagen del fútbol e incitaban igualmente a la violencia y al desorden, así como a la protesta del aficionado. La comisión le impuso una sanción disciplinaria de suspensión de doce partidos oficiales y una multa de unos 6.058 euros. El club demandante impugnó la decisión argumentando que las expresiones del jugador eran pacíficas, que no incitaban a la violencia y que estaban protegidas por los arts. 9 y 10 del Convenio.

El comité de arbitraje confirmó las medidas disciplinarias. 


\section{Asunto Ibrahim Tokmak}

El demandante era árbitro en el momento en el que se produjeron los hechos. Compartió en su cuenta de Facebook una publicación de un tercero en la que se expresaba que H. K., un cronista y editor de un diario, había fallecido por una crisis cardíaca tras haber tomado un medicamento utilizado para el tratamiento de la disfunción eréctil.

La comisión de disciplina deportiva consideró que la publicación infringía la normativa aplicable y, por consiguiente, le impuso una sanción disciplinaria de suspensión de tres meses. El comité de arbitraje confirmó la sanción.

Ante el TEDH, los demandantes cuestionan la imparcialidad e independencia del comité de arbitraje, desde un punto de vista orgánico y económico. El señor Doğan dice que los miembros de esta instancia son nombrados por el presidente de la Federación Turca de Fútbol y que la duración de su mandato está limitada al mandato del presidente. En base al art. 10 (libertad de expresión), todos los demandantes alegan que las sanciones impuestas atentan contra su libertad de expresión. Asimismo, el señor Doğan, en base al art. $7 \mathrm{CEDH}$, dice que ha sido objeto de procesamientos arbitrarios. En base al art. 13, el señor Doğan añade que no ha podido impugnar las decisiones del comité de arbitraje ante un tribunal.

El TEDH comienza su argumentación recordando que en su sentencia $A l i$ Riza y otros c. Turquía, de 28 de enero de 2020, constató que había deficiencias estructurales en el comité de arbitraje que derivan de los vastos poderes otorgados al consejo de administración de la Federación en lo que concierne al funcionamiento y organización del comité. Debido a la ausencia de garantías adecuadas que protejan a los miembros del comité contra presiones externas, especialmente las del consejo de administración, el TEDH concluyó que hay razones legítimas para dudar de la independencia e imparcialidad de sus miembros.

Por las mismas razones, el TEDH concluye que ha habido una violación del art. 6.1 CEDH en cada uno de los asuntos que se plantean en esta ocasión.

En cuanto a las alegaciones en relación con el art. $10 \mathrm{CEDH}$, el TEDH observa que las injerencias en cada caso tenían una base legal y que perseguían los fines legítimos de defensa del orden, de la prevención del delito y de la protección de la reputación de los demás.

En el asunto Sedat Doğan, el TEDH observa que la motivación ofrecida por las autoridades internas para sancionar al demandante no le permiten concluir que haya habido una ponderación adecuada de los derechos e intereses en conflicto. No han demostrado que los hechos acontecidos hayan incitado o pudieran incitar a los aficionados a la comisión de actos de violencia.

En el asunto Naki y Amed Sportif Faaliyetler Kulübü Derneği, el TEDH dice que ni la comisión de disciplina ni el comité de arbitraje especifican qué partes del mensaje eran problemáticas a su modo de ver ni han examinado el contexto de la publicación, a saber, la victoria del equipo demandante en un partido de 
fútbol tras unos actos violentos acontecidos en la región. El TEDH subraya que las autoridades nacionales no han demostrado que se haya incitado a la violencia.

En el asunto Ibrahim Tokmak, el Tribunal observa que la comisión de disciplina y el comité de arbitraje han estimado que los árbitros, considerados como la única autoridad del fútbol en el terreno en tanto que representantes de la Federación, deben ser muy cuidadosos con su vida social y su comportamiento habida cuenta de la fragilidad del clima de paz en el ámbito del fútbol y la necesidad de preservar una imagen de objetividad e imparcialidad de las autoridades de este espectáculo deportivo. La comisión de disciplina y el comité de arbitraje han considerado que la publicación contenía expresiones irrespetuosas con la memoria de una persona fallecida. El TEDH considera que la publicación puede tener un contenido considerado indecente e injurioso y contrario a los valores de la cultura moral, nacional o deportiva. Empero, la sanción no se ha justificado en aras a fines legítimos como la protección del orden, la prevención del delito ni ha sido proporcionada a la protección de tales fines. Las autoridades no han valorado tampoco la dureza de la sanción ni el efecto disuasorio que podría tener en el demandante y otros profesionales en el ejercicio de la libertad de expresión.

Por todo ello, el TEDH considera que ha habido una violación de la libertad de expresión en cada asunto.

A la vista de las argumentaciones ofrecidas en base al art. $10 \mathrm{CEDH}$, el TEDH considera innecesario pronunciarse sobre la violación del resto de los preceptos alegados.

\section{PROHIBICIÓN DE DISCRIMINACIÓN EN EL OTORGAMIENTO DE AYUDAS FAMILIARES EN SITUACIONES ANÁLOGAS}

En la sentencia recaída en el caso Yocheva y Ganeva c. Bulgaria, de 11 de mayo de 2021, las demandantes son madres solteras. El ordenamiento interno contempla una ayuda familiar para los menores huérfanos de uno de los progenitores. Las demandantes la solicitaron. La Administración desestimó ambas solicitudes. En el caso de la señora Yocheva, la Administración consideró que no se probó que el padre hubiera reconocido al menor ni que hubiera fallecido. En el caso de la señora Ganeva, la Administración rechazó la solicitud porque el padre es desconocido. Las demandantes acuden ante el TEDH alegando que la ayuda familiar contemplada en la ley discrimina por razones personales, familiares y de origen.

El TEDH admite la demanda de la primera demandante, mientras que inadmite la de la segunda demandante, ya que presentó el recurso fuera de plazo.

El TEDH observa que la primera demandante, la señora Yocheva, se encuentra en una situación similar en relación con los viudos cuyos hijos han nacido en el matrimonio y con las madres solteras cuyos hijos han sido reconocidos por los 
progenitores antes de fallecer. Por ello, el TEDH analiza si ha habido una diferencia de trato.

La solicitud de ayuda de la primera demandante se desestimó porque no pudo probar que el padre había fallecido y que los hijos eran sus herederos legales a diferencia de otros grupos de familias que pueden solicitar la ayuda, ya que pueden aportar los documentos acreditativos del vínculo legal de los niños con ambos progenitores. Por ello, el TEDH dice que ha habido una diferencia de trato entre la familia de la primera demandante y otros grupos.

El TEDH analizará si la diferencia de trato se ha debido a las circunstancias previstas en el art. $14 \mathrm{CEDH}$.

La primera demandante ha sido tratada de una manera diferente por razón de sexo y por sus circunstancias familiares.

En cuanto a la discriminación por razón de sexo, el TEDH argumenta que la maternidad se determina por el acto de nacimiento. La paternidad, sin embargo, en casos como el presente, es más difícil de determinar. Como madre de un niño de padre desconocido, no puede proporcionar los documentos que exige la ley, mientras que un padre soltero cuya madre ha fallecido normalmente podrá hacerlo.

En cuanto a la discriminación por sus circunstancias familiares, la demandante ha sido discriminada en su condición de madre soltera que no ha podido determinar la identidad del padre del niño. El derecho interno solo ofrece las ayudas a las familias con un padre sobreviviente.

El TEDH analiza, a continuación, si la diferencia de trato ha sido objetiva. El TEDH sostiene que el Gobierno no ha ofrecido una justificación objetiva o razonable para excluir a la familia de la demandante como beneficiaria de la ayuda. El TEDH subraya que la diferencia de trato que dimana de la ley aplicable se basa en una concepción muy tradicional, trasnochada y estereotipada del instituto de la familia, como aquel que necesariamente contempla dos padres legales. Ello no justifica la diferencia de trato, como tampoco otros estereotipos basados en la raza, el sexo o la orientación sexual.

El condicionamiento de la concesión de la ayuda a la revelación de información intima de la demandante y a la adopción de pasos legales para el reconocimiento paterno del menor, lo que afectaba de lleno a su vida privada y que no deseaba hacer, equivalía a condicionar el pleno ejercicio de su derecho al respeto de su vida familiar a que renunciara al ejercicio de su derecho al respeto de su identidad personal y social y su integridad psicológica, protegidas por el art. $8 \mathrm{CEDH}$.

Los niños cuyos padres son desconocidos, en términos objetivos, han sido privados del cuidado y la protección de uno de los progenitores de la misma manera que los nińos cuyos padres han fallecido. No puede decirse que necesitan menos cuidados y protección que los últimos o que se encuentran en una mejor posición, sin tener en cuenta un conjunto amplio de circunstancias contextuales de importancia que inevitablemente varían en cada caso. 
La situación de la familia de la primera demandante, que, según ella, se caracteriza por una ausencia absoluta de un padre, no puede considerarse como una situación ventajosa con respecto de la situación de los nińos que contempla la ley búlgara.

El TEDH tiene en cuenta que el Gobierno ha observado que la finalidad de la ley en cuanto a la exigencia de la identidad del padre es la prevención del fraude, si bien no ha argumentado en ningún caso que este fuera el propósito de la demandante. El TEDH tiene en cuenta también que el Gobierno no ha acreditado que el fraude esté generalizado en esta materia o que otras medidas a tal fin sean ineficaces.

El TEDH constata que no hay un estándar común en cuanto a los sistemas de ayudas sociales. Asimismo, recuerda que hay un amplio margen de apreciación en materia de política económica y social. No obstante, todo ello no autoriza a los Estados a conceder las ayudas en base a criterios discriminatorios sin una justificación objetiva y razonable. Además, en el presente caso el Gobierno no ha demostrado que el padre desconocido del niño colaborara en sus cuidados.

A la vista de todas las circunstancias descritas, el TEDH concluye que el Gobierno no ha ofrecido razones convincentes referidas al sexo de la demandante o sus circunstancias familiares para justificar el efecto discriminatorio de la ley aplicable en su familia. Por ello, el TEDH resuelve, por unanimidad, que ha habido una discriminación en el ejercicio del derecho al respeto de la vida privada y familiar (art. $14+8 \mathrm{CEDH})$. 